\title{
NC Milling Deformation Forecasting of Aluminum Alloy Thin- Walled Workpiece Based on Orthogonal Cutting Experiments and CAD/CAM/FEA Integration Paper Title
}

\author{
Yan Cao ${ }^{1}$, Yu Bai ${ }^{1}$, Yongqiang He ${ }^{1}$, Jianhui Tian ${ }^{1}$ and Yunlong $\mathrm{Li}^{2}$ \\ ${ }^{1}$ School of Mechatronic Engineering, Xi'an Technological University, Xi'an, P.R. \\ China \\ ${ }^{2}$ School of Mechanical Engineering, Xi'an Jiaotong University, Xi'an, P.R.China \\ jantonyz@163.com (Yan Cao)
}

\begin{abstract}
Thin-walled components have characteristics of high intensity and light mass and are used widely in aeronautical industry. NC milling is one of the most popular machining methods for the thin-walled components. Because of their poor rigidity, the deformation of the thin-walled workpieces caused by cutting force is a main factor that decreases the machining precision and increases aeronautical product cost. Based on the analyses of the machining deformation mechanism and basic machining deformation characteristics of the thin-walled workpieces, a NC milling deformation forecasting approach is presented based on CAD/CAM/FEA integration to forecast the machining deformation of the aeronautical thin-walled workpieces. Taking a typical workpiece for example, the proposed deformation forecast framework is validated by the analytic and experimental results. The straight side walls of aluminum LY12CZ workpieces are processed on a vertical machining center THA5656 and their errors are analyzed. Based on orthogonal tests, the deformation characters of the thin-walled workpieces are discussed under different cutting conditions. By the comparison of experimental results and FEA results, although there exist definite difference, their variation tendencies are similar on the whole. Thus, the FEA model is validated. The research can provide support for machining deformation control and machining simulation model verification.
\end{abstract}

Keywords: Thin-walled workpiece; NC milling; Machining deformation; CAD/CAM/FEA; Aluminum alloy; Orthogonal test; Error analysis; Deformation Forecasting

\section{Introduction}

In their milling process, thin-walled workpieces are prone to deform under the action of cutting force because of their poor rigidity, residual stress release, etc. It affects the size, form and position accuracies of the workpieces badly. In order to assure the accuracies of the thinwalled workpieces, it is necessary to study the deformation mechanism and characteristics of the thin-walled workpieces in numerical control (NC) machining. Effective deformation forecasting of the thin-walled workpieces is the precondition of effective deformation control measures.

In actual machining of the aeronautical thin-walled workpiece, in order to compensate the deformation error in NC milling, a lot of trial cuts are usually adopted where machining parameters are improved iteratively to reduce machining deformation error. After the workpiece is milled, manual or mechanical deformation correction is needed. But this leads to stress concentration in the corrected aluminum alloy workpiece. Besides, because the 
deformation correction depends greatly on human factor, its great blindness and randomness affect machining accuracy of the workpiece badly.

With the development and application of CAD/CAM/CAE in manufacturing, deformation forecasting and control technologies based on Finite Element Analysis (FEA) provide effective approaches for systematically studying the machining deformation rules and control methods of the aeronautical thin-walled workpieces [1-6]. In the paper, CAD/CAM/FEA is used to study the machining deformation forecasting of the aeronautical thin-walled workpieces to assure production efficiency and machining accuracy.

\section{NC milling Deformation Forecasting of the Thin-walled Workpiece based on CAD/CAM/FEA Integration}

It needs a lot of data to study the machining deformation of aeronautical thin-walled workpiece. If the data are obtained completely through machining experiments, the costs are too expensive. In the paper, different professional CAD/CAM/FEA systems are integrated to study the NC milling deformation forecasting of the thin-walled workpiece [7], as shown in Figure 1. The flow of NC milling process simulation of the thin-walled workpiece is shown in Figure 2.

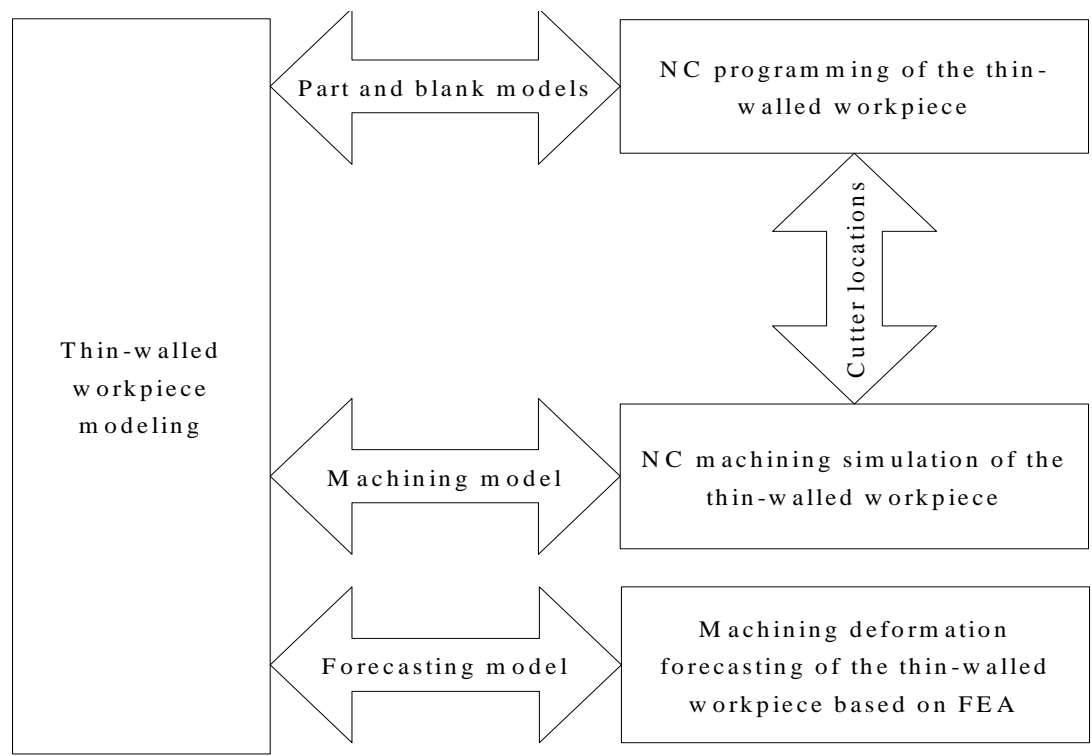

Figure 1. NC Milling Deformation Forecasting of the Thin-walled Workpiece

After analyzing the thin-walled workpiece to be machined, the three-dimensional models of the workpiece and its blank are established using SolidWorks. Then, the NC programs are completed using Mastercam that are simulated using NC machining simulation system VERICUT. Besides, the machining models corresponding to each machining operation are generated and imported into SolidWorks using a data interface. Then, the deformation of the thin-walled workpiece is analyzed using Ansys under different machining conditions. 


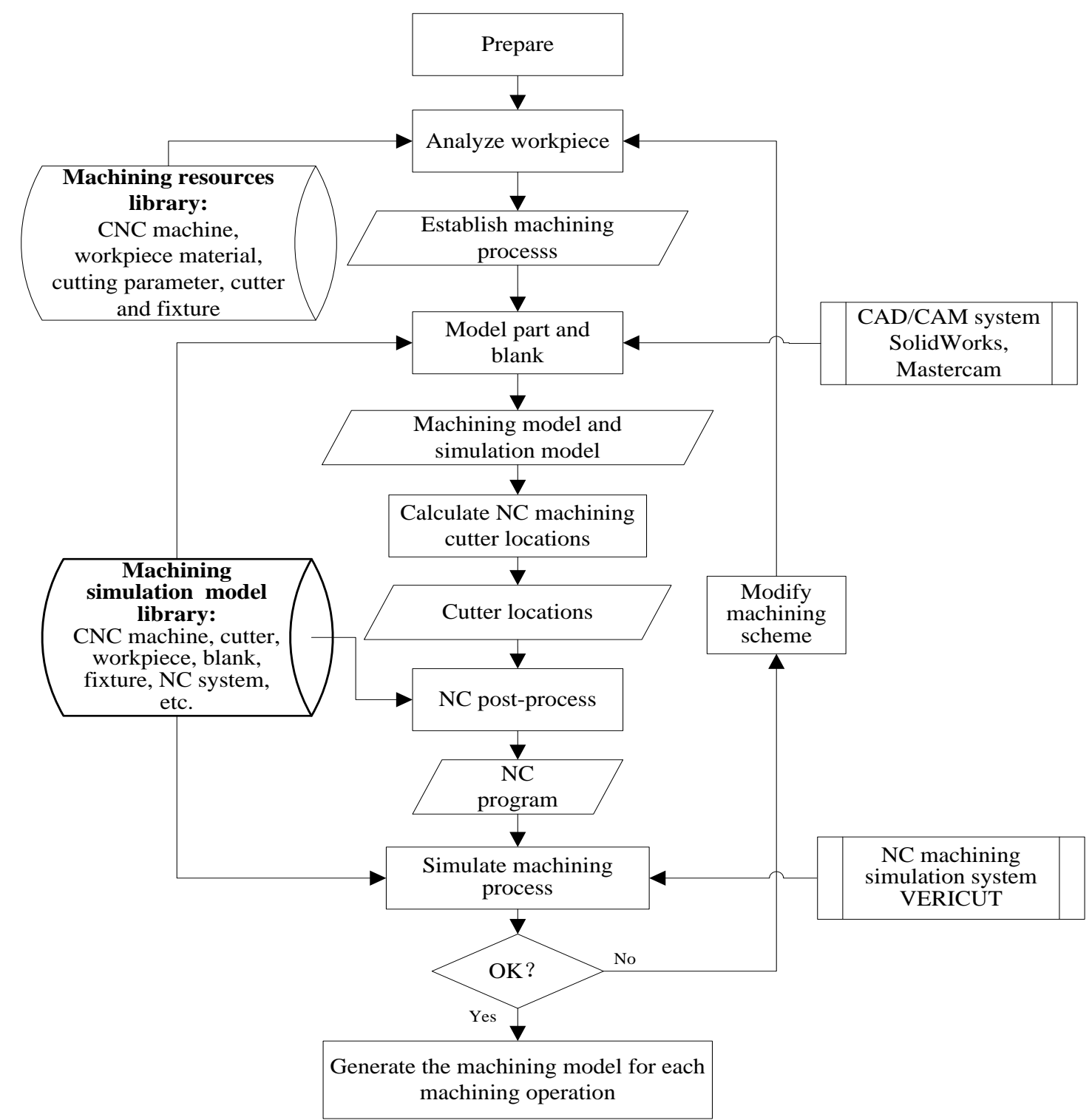

Figure 2. The Flow of NC Milling Process Simulation of the Thin-walled Workpiece

\section{Milling Test Scheme}

In recent years, machining deformation control technology has been gained extensive attention from domestic and foreign researchers. Due to the complexity of machining process itself, substantive further work is still needed. In the paper, the machining deformation of thin-walled workpieces is studied through milling tests. The rectangular straight side walls of aluminum alloy LY12CZ (hot rolled plate GB3193-82) workpieces are milled based on orthogonal tests to study the influence of cutting parameters on machining deformation in finishing machining. It can provide support for improving productivity and controlling machining deformation. And, the research can also be helpful to thin-walled workpiece process planning and cutting parameter selection. Accordingly, it is of great importance for improving the machining precision of the thin-walled workpieces. 


\subsection{Machine Tool, Tools, and Workpiece Material}

The machining test conditions are as follows.

- The tools are $\Phi 4$ three-wing end milling cutter whose material is high-speed steel W18Cr4V.

- The workpiece material is aluminum LY12CZ (hot rolled plate GB3193-82, $\sigma_{b}$ $=510 \mathrm{~N} / \mathrm{mm}^{2}, \sigma_{0.2}=373 \mathrm{~N} / \mathrm{mm}^{2}$, and HB130).

- The machine tool adopts THA5656 vertical machining center. Conventional milling is adopted as the milling mode. THA5656 vertical machining center uses Japanese FANUC-0MC numerical control system and is controlled by CNC micro-computer. It possesses 4-axis coupled function.

- The milling parameters are milling speed $v$, milling depth $a_{p}$, milling width $a_{e}$ , cutter diameter $d_{0}$, and feed amount $f$.

\subsection{Orthogonal Test Scheme}

The side walls of the workpieces are milled under different cutting conditions and the deformation is measured. In the paper, milling speed $v$, milling depth $a_{p}$, milling width $a_{e}$, and feed amount $f$ are mainly considered. The orthogonal tests are determined adopting four factors and three levels, as shown in Table 1. The orthogonal table L9 $\left(3^{4}\right)$ is shown in Table 2 .

Table 1. Four Factors and Three Levels

\begin{tabular}{|c|c|c|c|c|}
\hline Level Factor & ${ }^{v}(\mathbf{r} / \mathbf{m i n})$ & ${ }^{f}(\mathbf{m m} / \mathbf{m i n})$ & ${ }^{a_{p}}(\mathbf{m m})$ & ${ }^{a}{ }(\mathbf{m m})$ \\
\hline 1 & 2000 & 100 & 5 & 0.3 \\
\hline 2 & 2500 & 150 & 7 & 0.2 \\
\hline 3 & 3000 & 200 & 10 & 0.1 \\
\hline
\end{tabular}

Table 2. Test Parameters

\begin{tabular}{|c|c|c|c|c|}
\hline Test & $v$ & $f$ & $a_{p}$ & $a_{e}$ \\
\hline 1 & $1(2000 \mathrm{r} / \mathrm{min})$ & $1(100 \mathrm{~mm} / \mathrm{min})$ & $1(5 \mathrm{~mm})$ & $1(0.3 \mathrm{~mm})$ \\
\hline 2 & $1(2000 \mathrm{r} / \mathrm{min})$ & $2(150 \mathrm{~mm} / \mathrm{min})$ & $2(7 \mathrm{~mm})$ & $2(0.2 \mathrm{~mm})$ \\
\hline 3 & $1(2000 \mathrm{r} / \mathrm{min})$ & $3(200 \mathrm{~mm} / \mathrm{min})$ & $3(10 \mathrm{~mm})$ & $3(0.1 \mathrm{~mm})$ \\
\hline 4 & $2(2500 \mathrm{r} / \mathrm{min})$ & $1(100 \mathrm{~mm} / \mathrm{min})$ & $2(7 \mathrm{~mm})$ & $3(0.1 \mathrm{~mm})$ \\
\hline 5 & $2(2500 \mathrm{r} / \mathrm{min})$ & $2(150 \mathrm{~mm} / \mathrm{min})$ & $3(10 \mathrm{~mm})$ & $1(0.3 \mathrm{~mm})$ \\
\hline 6 & $2(2500 \mathrm{r} / \mathrm{min})$ & $3(200 \mathrm{~mm} / \mathrm{min})$ & $1(5 \mathrm{~mm})$ & $2(0.2 \mathrm{~mm})$ \\
\hline 7 & $3(3000 \mathrm{r} / \mathrm{min})$ & $1(100 \mathrm{~mm} / \mathrm{min})$ & $3(10 \mathrm{~mm})$ & $2(0.2 \mathrm{~mm})$ \\
\hline 8 & $3(3000 \mathrm{r} / \mathrm{min})$ & $2(150 \mathrm{~mm} / \mathrm{min})$ & $1(5 \mathrm{~mm})$ & $3(0.1 \mathrm{~mm})$ \\
\hline 9 & $3(3000 \mathrm{r} / \mathrm{min})$ & $3(200 \mathrm{~mm} / \mathrm{min})$ & $2(7 \mathrm{~mm})$ & $1(0.3 \mathrm{~mm})$ \\
\hline
\end{tabular}




\section{Milling Tests and Result Analysis}

\subsection{Milling Tests}

According to the above test scheme, the workpiece side walls are machined to $1 \mathrm{~mm}$ thick and multiple times of smoothing milling are executed to guarantee their shape accuracy, as shown in Figure 3.

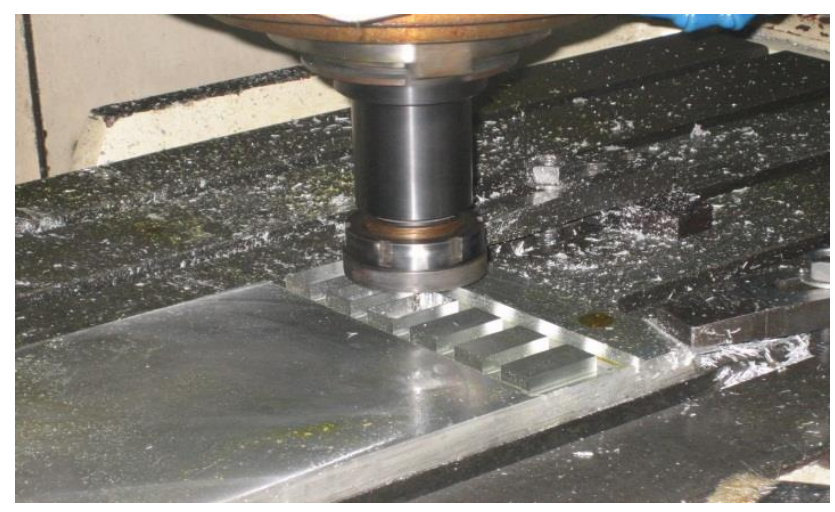

Figure 3. Rectangular Pocket Milling

The finishing machining conditions are listed in Table 2. The dimensions of the side walls are $\mathrm{L}=40 \mathrm{~mm}$ long, $\mathrm{H}=10 \mathrm{~mm}$ high, and $\mathrm{W}=1 \mathrm{~mm}$ thick. The suspending length o the threewing $\Phi 4$ end milling cutter is $14 \mathrm{~mm}$ whose helical angle is $30^{\circ}$.

In order to study the deformation of the side walls, after the milling is finished, the deformation of the side walls is measured from above to below along $\mathrm{Z}$ axis at $\mathrm{x} 1=10, \mathrm{x} 2=20$, and $\times 3=30$ locations using a micrometer gauge before the workpiece is disassembled. Thus, the deformation of the milled side walls can be obtained. The distance between two measuring points is $1 \mathrm{~mm}$, as shown in Figure 4.

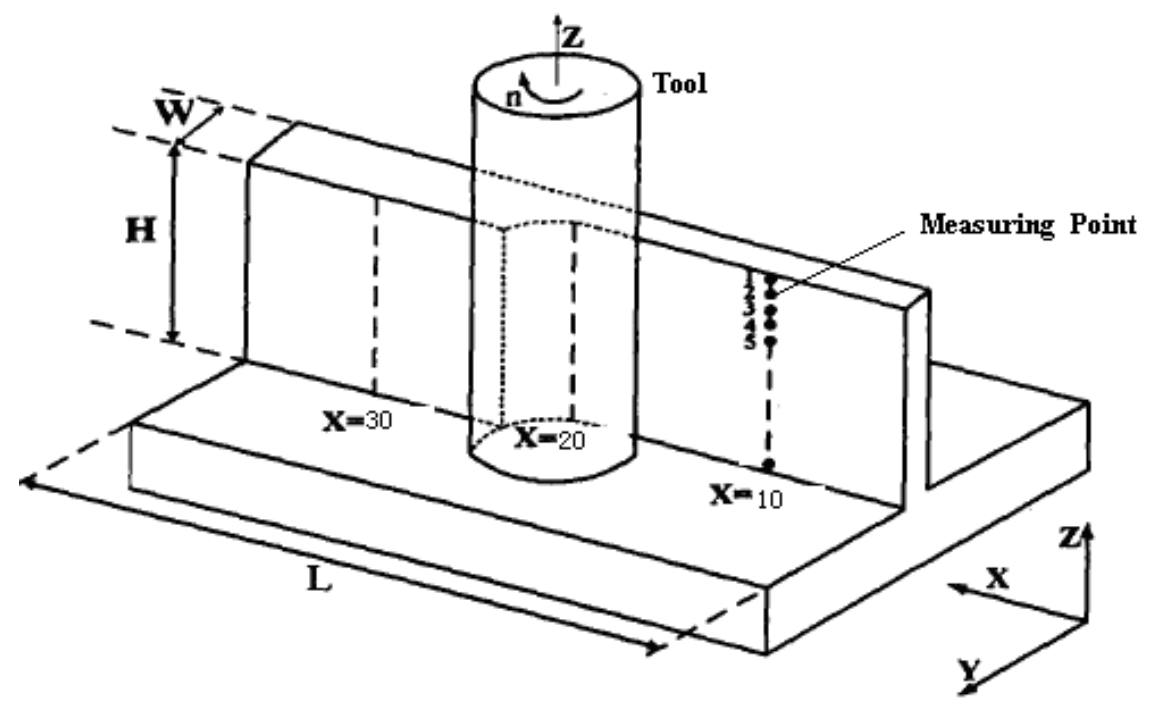

Figure 4. Deformation Measuring Scheme

\subsection{Test Results and Analysis}

The test results of test 3, 5, and 7 are as follows. 
In test $3\left(v=2000 \mathrm{r} / \mathrm{min}, f=200 \mathrm{~mm} / \mathrm{min}, a_{p}=10 \mathrm{~mm}\right.$, and $\left.a_{e}=0.1 \mathrm{~mm}\right)$, the test results are shown in Table 3 and Figure 5. The deformation range is $-0.024 \sim 0.001 \mathrm{~mm}$. The position of the largest deformation is at $\mathrm{X} 2=20 \mathrm{~mm}$ and measuring point 2 along $\mathrm{Z}$-axis direction.

Table 3. Deformation at $\times 1, \times 2$, and $\times 3$ in Test $3(\mathrm{~mm})$

\begin{tabular}{|c|c|c|c|}
\hline $\begin{array}{c}\text { Measuring } \\
\text { point }\end{array}$ & $\begin{array}{c}\text { Deformation at } \\
\mathbf{x 1 = 1 0 m m}\end{array}$ & $\begin{array}{c}\text { Deformation at } \\
\mathbf{x} \mathbf{2}=\mathbf{2 0} \mathbf{m m}\end{array}$ & $\begin{array}{c}\text { Deformation at } \\
\mathbf{x} \mathbf{3}=\mathbf{3 0} \mathbf{m m}\end{array}$ \\
\hline 1 & -0.002 & 0 & -0.003 \\
\hline 2 & -0.0025 & 0.001 & -0.0035 \\
\hline 3 & -0.010 & -0.011 & -0.010 \\
\hline 4 & -0.012 & -0.015 & -0.011 \\
\hline 5 & -0.016 & -0.016 & -0.016 \\
\hline 6 & -0.021 & -0.020 & -0.022 \\
\hline 7 & -0.024 & -0.022 & -0.022 \\
\hline 8 & -0.024 & -0.022 & -0.022 \\
\hline 9 & -0.022 & -0.022 & -0.021 \\
\hline 10 & -0.020 & -0.020 & -0.020 \\
\hline
\end{tabular}

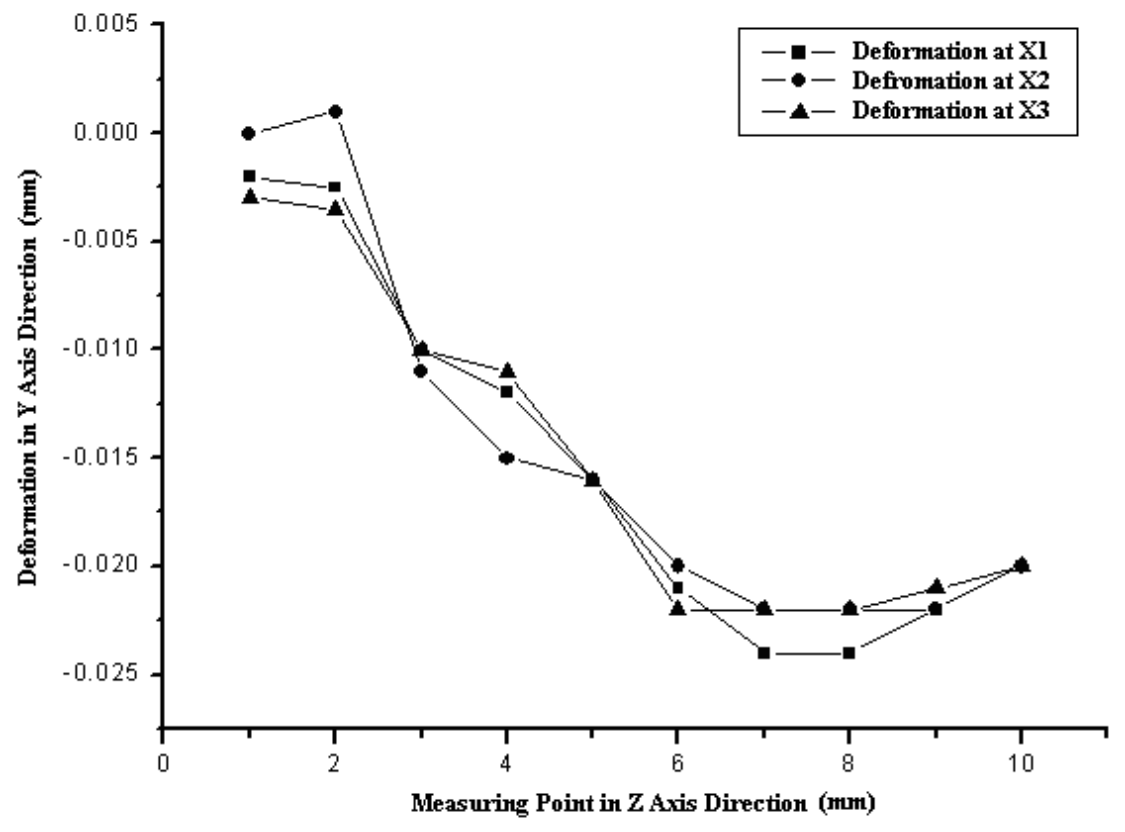

Figure 5. Deformation in Test 3

In test $5\left(v=2500 \mathrm{r} / \mathrm{min}, f=150 \mathrm{~mm} / \mathrm{min}, a_{p}=10 \mathrm{~mm}\right.$, and $\left.a_{e}=0.3 \mathrm{~mm}\right)$, the test results are shown in Table 4 and Figure 6 . The deformation range is $-0.045 \sim 0 \mathrm{~mm}$. The position of the largest deformation is at $\mathrm{X} 2=20 \mathrm{~mm}$ and measuring point 1 along $\mathrm{Z}$-axis direction.

In test $7\left(v=3000 \mathrm{r} / \mathrm{min}, f=100 \mathrm{~mm} / \mathrm{min}, a_{p}=10 \mathrm{~mm}\right.$, and $\left.a_{e}=0.2 \mathrm{~mm}\right)$, the test results are shown in Table 5 and Fig.5. The deformation range is $-0.028 \sim 0 \mathrm{~mm}$. The position of the largest deformation is at $\mathrm{X} 2=20 \mathrm{~mm}$ and measuring point 2 along $\mathrm{Z}$-axis direction. 
Table 4. Deformation at $\times 1, \times 2$, and $\times 3$ in test $5(\mathrm{~mm})$

\begin{tabular}{|c|c|c|c|}
\hline $\begin{array}{c}\text { Measuring } \\
\text { point }\end{array}$ & $\begin{array}{c}\text { Deformation at } \\
\mathbf{x 1 = 1 0 m m}\end{array}$ & $\begin{array}{c}\text { Deformation at } \\
\mathbf{x 2 = 2 0} \mathbf{m m}\end{array}$ & $\begin{array}{c}\text { Deformation at } \\
\mathbf{x} \mathbf{3}=\mathbf{3 0} \mathbf{m m}\end{array}$ \\
\hline 1 & -0.010 & 0 & -0.012 \\
\hline 2 & -0.015 & -0.005 & -0.016 \\
\hline 3 & -0.028 & -0.022 & -0.030 \\
\hline 4 & -0.033 & -0.030 & -0.034 \\
\hline 5 & -0.0336 & -0.030 & -0.0326 \\
\hline 6 & -0.044 & -0.040 & -0.043 \\
\hline 7 & -0.0416 & -0.038 & -0.040 \\
\hline 8 & -0.042 & -0.040 & -0.041 \\
\hline 9 & -0.041 & -0.038 & -0.040 \\
\hline 10 & -0.037 & -0.037 & -0.037 \\
\hline
\end{tabular}

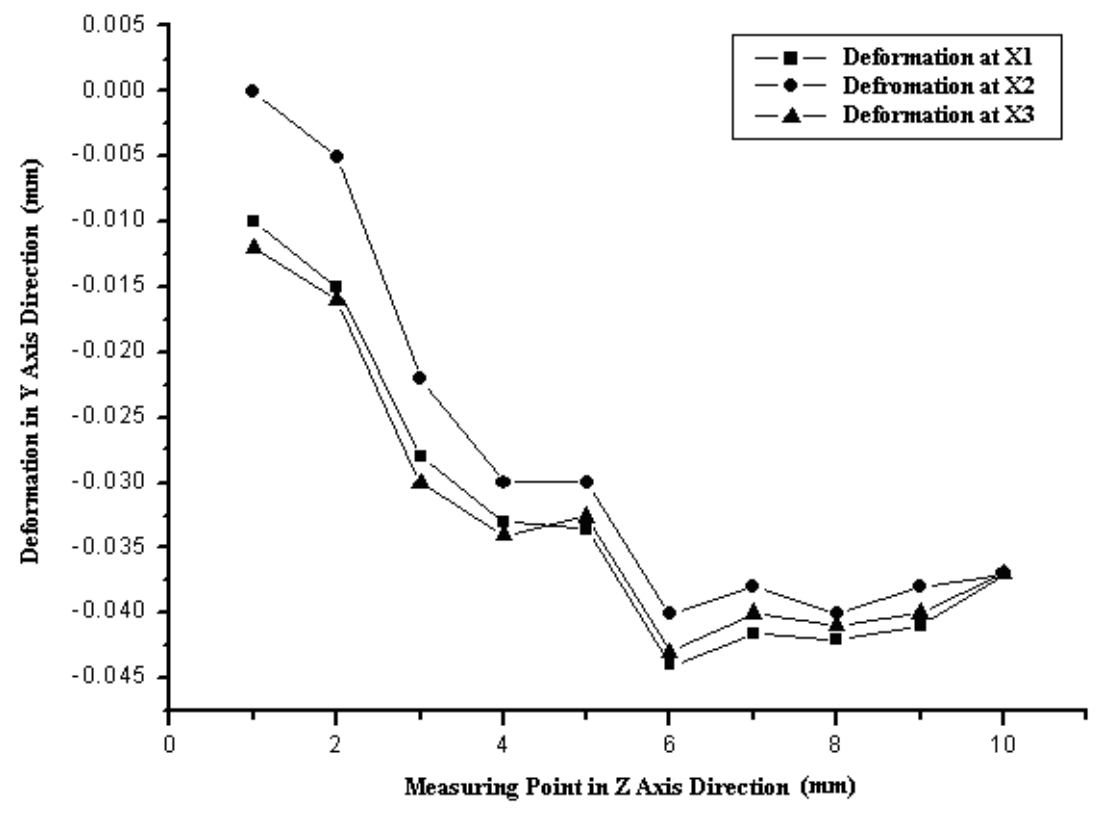

Figure 6. Deformation in Test 5

As can be seen from the above results, the difference at the lower sections of $\mathrm{X} 1, \mathrm{X} 2$, and $\mathrm{X} 3$ locations is small, but the difference at the upper section of $\mathrm{X} 1, \mathrm{X} 2$, and $\mathrm{X} 3$ locations is comparatively large. While the material is removed from the side walls of the workpieces, the rigidity of the upper section of the side wall at X1, X2, and X3 locations decreases dramatically. As a result, the milling deformation of the side walls increases. Because the rigidity of the lower section of the side walls is comparatively stable, the deformation of the lower section is smaller than that of the upper section of the side walls. The deformation of the bottom section of the side walls is very small because the workpieces is machined on a large block of aluminum alloy plate in the tests. 
Table 5. Deformation at $\times 1, \times 2$, and $\times 3$ in Test $7(\mathrm{~mm})$

\begin{tabular}{|c|c|c|c|}
\hline $\begin{array}{c}\text { Measuring } \\
\text { point }\end{array}$ & $\begin{array}{c}\text { Deformation at } \\
\mathbf{x 1 = 1 0 m m}\end{array}$ & $\begin{array}{c}\text { Deformation at } \\
\mathbf{x 2 = 2 0} \mathbf{m m}\end{array}$ & $\begin{array}{c}\text { Deformation at } \\
\mathbf{x} \mathbf{3}=\mathbf{3 0} \mathbf{m m}\end{array}$ \\
\hline 1 & -0.0006 & 0 & -0.001 \\
\hline 2 & -0.0026 & 0.0002 & -0.002 \\
\hline 3 & -0.015 & -0.012 & -0.016 \\
\hline 4 & -0.020 & -0.016 & -0.020 \\
\hline 5 & -0.018 & -0.015 & -0.018 \\
\hline 6 & -0.025 & -0.022 & -0.028 \\
\hline 7 & -0.024 & -0.022 & -0.024 \\
\hline 8 & -0.024 & -0.022 & -0.024 \\
\hline 9 & -0.024 & -0.022 & -0.0236 \\
\hline 10 & -0.022 & -0.020 & -0.022 \\
\hline
\end{tabular}

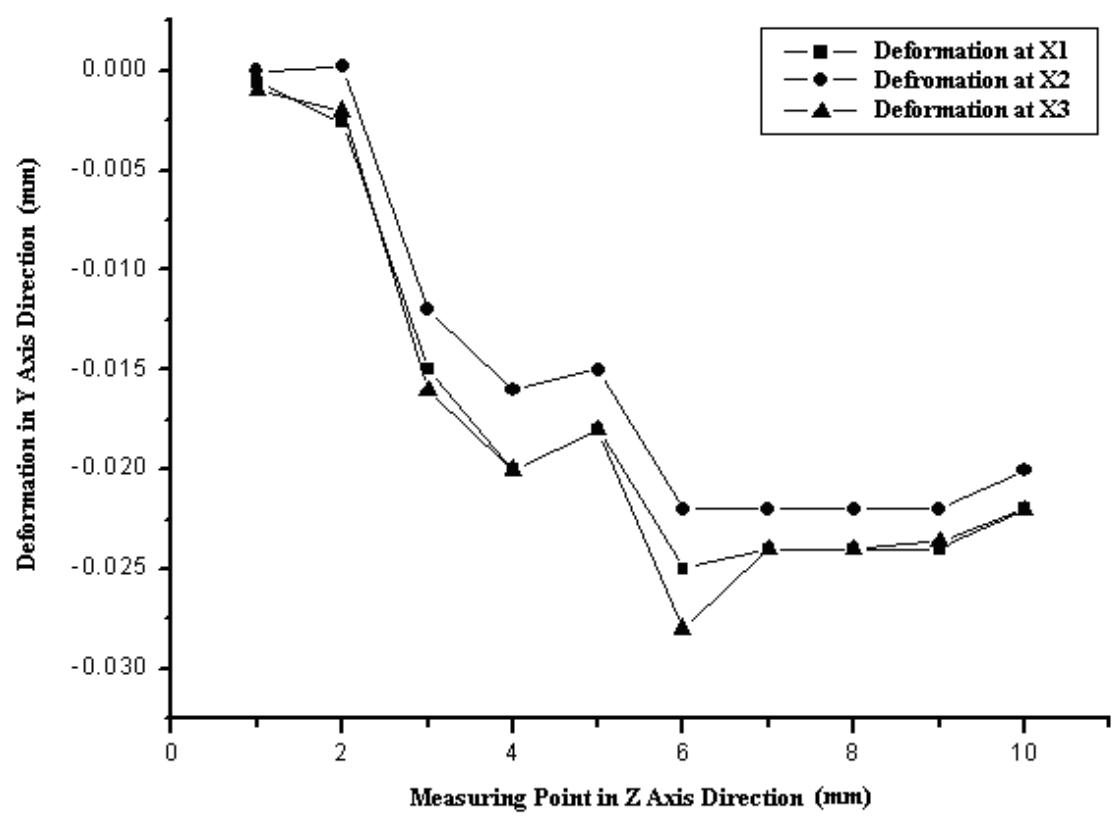

Figure 7. Deformation in Test 7

\section{Cutting Force Models}

The milling force is important for milling mechanism, cutter design, machine design, fixture design, and cutting parameter selection. The commonly used milling force models are as follows.

(1) Kline average force model and its modification.

The cutting force is related to cutting area. The whole cutting area is divided into tiny elements. After calculate the force on each tiny element, the distribution of the force on the cutting area is obtained. The total cutting force is equal to the sum of all the forces on the tiny elements as below. 


$$
\begin{aligned}
& \overline{F_{X}}=\sum_{j=1}^{N_{\theta}} \sum_{i=1}^{N_{Z}} \sum_{k=1}^{N_{f}}\left\{\mp K_{R} K_{T} D_{Z} f_{z} \sin ^{2}[\beta(i, j, k)]+K_{T} D_{z} f_{z} \cos [\beta(i, j, k)] \sin [\beta(i, j, k)]\right\} / N_{\theta} \\
& \overline{F_{Y}}=\sum_{j=1}^{N_{\theta}} \sum_{i=1}^{N_{Z}} \sum_{k=1}^{N_{f}}\left\{\mp K_{R} K_{T} D_{Z} f_{z} \sin [\beta(i, j, k)] \cos [\beta(i, j, k)]+K_{T} D_{z} f_{z} \sin ^{2}[\beta(i, j, k)]\right\} / N_{\theta}
\end{aligned}
$$

Where, minus sign is used for down milling and plus sign is used for upmilling. $\overline{F_{X}}$ and $\overline{F_{Y}}$ are the average force along $\mathrm{X}$-axis and $\mathrm{Y}$-axis of the machine respectively. $N_{\theta}$ is the angle number of each tooth angle space. $N_{z}$ is the number of elements. $N_{f}$ is the number of cutter teeth. $f_{z}$ is the feed rate per cutter tooth. $\beta(i, j, k)$ is the space angle of the ith element on the kth cutter tooth when the cutter is at the jth angle position. The model can be applied to calculate the cutting force when the cutter is at any position under any cutting condition.

Kline average force model takes many factors into account. But it is not very exact and its application is not wide.

(2) Force model based on unit force.

A great lot of researches show that it is a feasible approach to calculate cutting force based on unit force. The cutting force has relation to unit cutting force and cutting area. Literature [8] developed a universal machining system simulator that calculates cutting force according to empirical cutting force formula. It does not need a lot of cutting experiments. Based on the research of literature [8], literature [9] and [10] presented a milling force model suitable to milling deformation analysis of the thin-walled workpiece where a three-dimensional milling area is divided into tiny elements. The unit force components along $\mathrm{X}$-axis, $\mathrm{Y}$-axis and $\mathrm{Z}$-axis are as follows.

$$
\begin{aligned}
& F_{X}(i, j, k)=\left[C_{1} K_{n} \cos \left(\phi-\alpha_{r}\right)+K_{f} K_{n} C_{3} \cos \phi-K_{f} K_{n} C_{4} \sin \left(\phi-\alpha_{r}\right)\right] t_{c}(\phi) B_{1} \\
& F_{Y}(i, j, k)=\left[C_{1} K_{n} \sin \left(\phi-\alpha_{r}\right)+K_{f} K_{n} C_{3} \sin \phi+K_{f} K_{n} C_{4} \cos \left(\phi-\alpha_{r}\right)\right] t_{c}(\phi) B_{1} \\
& F_{Z}(i, j, k)=\left[-C_{2} K_{n}+K_{f} K_{n} C_{5}\right] t_{c}(\phi) B_{1}
\end{aligned}
$$

In the FEA deformation of the thin-walled workpiece, the stress of a side wall is different from that of a web. Therefore, different cutting force is constructed for different region respectively.

$\phi(i, j, k)$ is a value between $0 \sim 40^{\circ}$. The three-dimensional force model is stable and accurate. But its experimental cost is expensive and amount of calculation is large.

(3) Cutting force model based on multivariate linear regression analysis.

In high speed milling, the main cutting parameters are cutting speed (or spindle speed), feed rate, cutting depth and cutting width. Literature [11] constructed a milling force model through 7050-T7451 machining experiments as below.

$$
\begin{aligned}
& F_{X}=9.105 a_{p}{ }^{0.8974} v^{-0.4727} f^{0.0271} a_{e}{ }^{0.7813} d k \\
& F_{Y}=15.8 a_{p}{ }^{0.9190} v^{-0.4895} f^{0.0255} a_{e}{ }^{0.7983} d k \\
& F_{Z}=5.487 a_{p}{ }^{0.8431} v^{-0.5413} f^{0.0022} a_{e}{ }^{0.7277} d k
\end{aligned}
$$


Where, $\mathrm{k}$ is a correction coefficient related to cutting fluid. Usually, $\mathrm{k}=0.5 \sim 0.8$. Although this model is constructed for a given material, it can be applied to other homogeneous materials if $\mathrm{k}$ takes an appropriate value. In the paper, for $\mathrm{LY} 12 \mathrm{CZ}$ milling, $\mathrm{k}$ takes a slightly small value.

(4) Milling force model according to Mechanical Process Technic Handbook.

Mechanical Process Technic Handbook [12] provides cutting force formulas for mechanical processing personnel. According to Mechanical Process Technic Handbook, the empirical equation of milling force under given cutting conditions is as follows.

$$
F=0.25 \times 637 a_{p}{ }^{1.0} a_{f}{ }^{0.72} a_{e}{ }^{0.86} z d_{0}{ }^{-0.86} k_{F Z}
$$

Where, $F$ is circumferential component force. $a_{p}$ is milling depth. $a_{e}$ is milling width. $a_{f}$ is the feed rate per cutter tooth. $\mathrm{z}$ is the number of cuter teeth. $d_{0}$ is milling cutter diameter. $k_{F Z}$ is the coefficient of circumferential component force. $k_{F Z}$ is the correction factor of milling force whose value is $0.75 \sim 1.20 . k_{F Z}$ changes with milling conditions. Its value can be determined according to Mechanical Process Technic Handbook.

Although there is the difference of machining objects and environmental factors, the construction of cutting force model is similar. Different cutting force model pays attention to different factors and their coefficients. All the four cutting force models for milling aluminum alloy $\mathrm{LY} 12 \mathrm{CZ}$ are constructed. After analyzing the cutting force models in Matlab, the following conclusions are drawn.

(1) According to the published literature, in the milling process of the thin-walled workpiece, although the cutting force fluctuates, it lies in a comparatively narrow range. That is, the cutting force varies with time, but its extent is not large. Besides, because multiple cutter teeth of the cutter participate in the milling process, the cutting force tends to be stable. In the paper, the emphasis is concentrated on the deformation because of low rigidity. Therefore, for the convenience of computation, the cutting force variation is ignored and the average force is taken as the cutting force.

(2) Milling force model according to Mechanical Process Technic Handbook is used in the following FEA. The cutting force model can also be used to other material of approximative rigidity if the cutter parameters do not vary. If the cutter parameters change, the coefficients of the cutting force model should change too.

The perfect machining accuracy requests the optimal selection of cutting parameters. This is the further research topic. Besides, in the machining process of the thin-walled workpiece, cutting vibration, cutting heat and so on affect the cutting deformation too.

\section{Comparison of FEA Results and Experimental Results}

When processing the workpiece with milling depth $a_{p}=10 \mathrm{~mm}$ and milling width $a_{e}$ $=0.1 \mathrm{~mm}$, compare the FEA results with experimental results at $\mathrm{x} 1, \mathrm{x} 2$ and $\mathrm{x} 3$.

The FEA results are shown in Table 6 and the experimental results are shown in Table 7. 
Table 6. FEA Results

\begin{tabular}{|l|l|l|l|}
\hline Measuring point & \multicolumn{1}{|c|}{$\begin{array}{c}\text { Deformation at } \\
\mathbf{x 1 = 1 0 m m}\end{array}$} & $\begin{array}{c}\text { Deformation at } \\
\mathbf{x} \mathbf{2}=\mathbf{2 0} \mathbf{m m}\end{array}$ & $\begin{array}{c}\text { Deformation at } \\
\mathbf{x 3 = 3 0 m m}\end{array}$ \\
\hline 1 & -0.01329 & -0.0191 & -0.01249 \\
\hline 2 & -0.01079 & -0.01497 & -0.01008 \\
\hline 3 & -0.00901 & -0.01213 & -0.00816 \\
\hline 4 & -0.00729 & -0.00974 & -0.00671 \\
\hline 5 & -0.00589 & -0.00756 & -0.00514 \\
\hline 6 & -0.00439 & -0.00603 & -0.00397 \\
\hline 7 & -0.00309 & -0.00419 & -0.00272 \\
\hline 8 & -0.00179 & -0.00216 & -0.00151 \\
\hline 9 & $-5.90 \mathrm{E}-04$ & $-6.90 \mathrm{E}-04$ & $-4.20 \mathrm{E}-04$ \\
\hline 10 & $2.14 \mathrm{E}-04$ & $1.07 \mathrm{E}-04$ & $2.10 \mathrm{E}-04$ \\
\hline
\end{tabular}

Table 7. Experimental Results

\begin{tabular}{|l|l|l|l|}
\hline Measuring point & \multicolumn{1}{|c|}{$\begin{array}{c}\text { Deformation at } \\
\mathbf{x 1 = 1 0 m m}\end{array}$} & $\begin{array}{c}\text { Deformation at } \\
\mathbf{x} \mathbf{2}=\mathbf{2 0} \mathbf{m m}\end{array}$ & $\begin{array}{c}\text { Deformation at } \\
\mathbf{x} \mathbf{3}=\mathbf{3 0 m m}\end{array}$ \\
\hline 1 & -0.018 & -0.02 & -0.017 \\
\hline 2 & -0.0175 & -0.017 & -0.0165 \\
\hline 3 & -0.01 & -0.015 & -0.01 \\
\hline 4 & -0.008 & -0.01 & -0.009 \\
\hline 5 & -0.003 & -0.004 & -0.004 \\
\hline 6 & 0.002 & 0.002 & 0.002 \\
\hline 7 & 0.002 & 0.002 & 0.0015 \\
\hline 8 & 0.002 & 0.001 & 0.001 \\
\hline 9 & 0.001 & 0.001 & 0.001 \\
\hline 10 & 0.0002 & 0.0001 & 0.0002 \\
\hline
\end{tabular}

As shown in Figure 8, the maximal error at $\mathrm{x} 3$ between FEA results and experimental results is $0.00597 \mathrm{~mm}$. The tendency of deformation is identical.

Considering that there is measuring error in fact, the difference between experimental results and FEA results is small. The following conclusion can be drawn.

(1) After establishing the FEA model of the thin-walled workpiece in milling under different cutting conditions, the FEA model is verified by the deformation results of orthogonal tests under different cutting conditions.

(2) By the comparison of experimental results and FEA results, although there is definite difference, their variation tendencies are similar on the whole. The definite difference between experimental results and FEA results is at a comparatively fixed interval. Whether such a difference is led by the cutter, residual stress, or other factors needs further researches. 


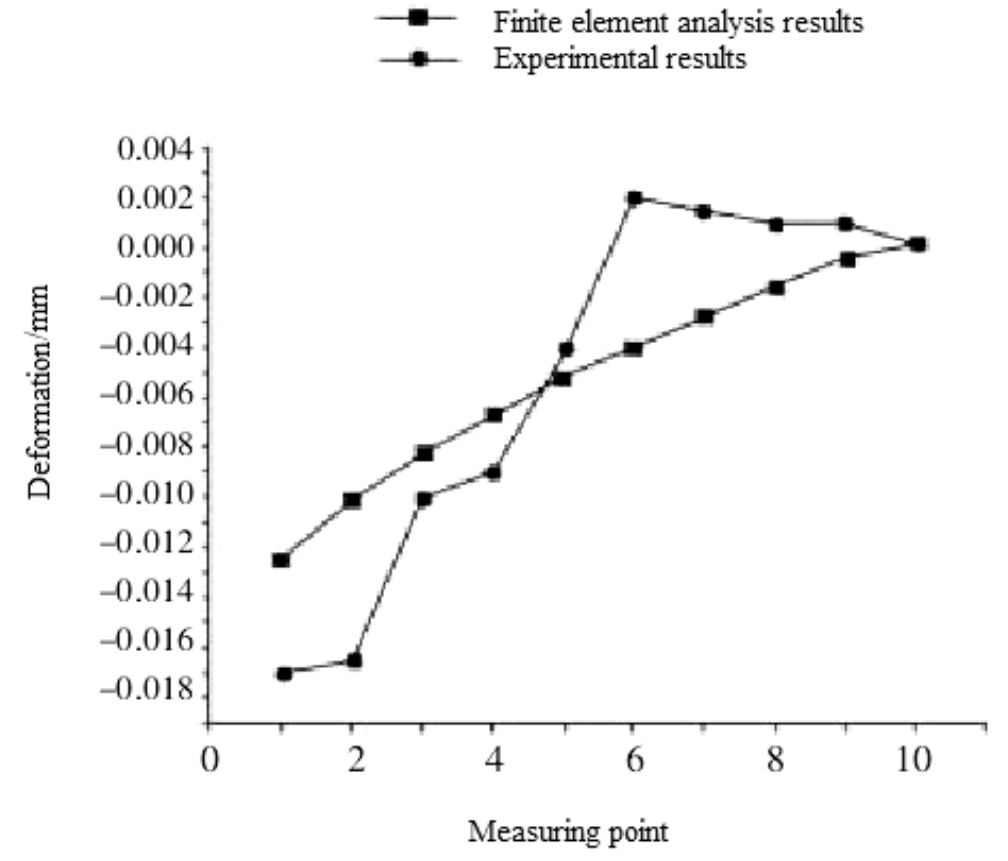

Figure 8. Comparison of FEA Results and Experimatal Results

\section{Conclusions}

Aiming at the NC milling deformation forecasting of aeronautical thin-walled workpieces, an approach is presented based CAD/CAM/FEA integration. Taking a typical structure of the aeronautical thin-walled workpieces for example, the approach is used to forecast the deformation of the thin-walled workpiece under different machining conditions.

Orthogonal tests are adopted to mill aluminum alloy LY12CZworkpieces under different cutting conditions. Then, the deformation of the milled side walls is measured and analyzed. The influence of different cutting parameters on deformation is discussed to improve productivity and control milling deformation. In order to study the deformation rule of thinwalled workpieces in milling process, a lot of data are needed. If all these data are obtained by cutting experiments, it is too expensive. Therefore, cutting experiments should be integrated with computer simulation of machining processes. By the comparison of experimental results and FEA results, the FEA model is verified by the deformation results of orthogonal tests under different cutting conditions. The research of the paper lays the foundation for machining deformation forecasting and $\mathrm{NC}$ milling process simulation model verification.

\section{Acknowledgements}

The work is supported by Natural Science Foundation Project of China (11302159), Key Problem Tackling Project of Shaanxi Scientific and Technological Office (2012K06-19), 2011 Key Education Innovation Project of Xi'an Technological University (11JGZ02), Natural Science Basic Research Plan in Shaanxi Province of China (2013JM7029) and Shaanxi Major Subject Construction Project. 


\section{References}

[1] Y. Cao, "Scientific Report on Machining Parameters and Stress Analysis of K192 Prestretching Plate, Xi' an, Xi' an Jiaotong University, (2003).

[2] Y. Cao, H. Chen and H. X. Zhao, "Analysis of the influence of cutting parameters on cutting force based on cutting process simulation”, Advanced Materials Research, vol. 7, no. 10, (2013), pp. 223-227.

[3] Y. Cao, S. Cao, Y. Bai and X. F. Yang, "CBR-Based cutting parameter selection system and searching algorithm for metal machining operations", Advanced Materials Research, vol. 7, no. 10, (2013), pp. 554557.

[4] Y. Cao, Y. Bai, Y. Q. He and Y. L. Li, "NC milling deformation analysis of aluminum alloy thin-walled components based on orthogonal cutting experiments on a vertical machining center", ICIMA 2010 - 2010 2nd International Conference on Industrial Mechatronics and Automation, vol. 2, (2010), pp. 91-94.

[5] Y. Bai, Y. Cao and X. F. Zhang, "Standardization and system implementation of cutting parameter selection process", Advanced Materials Research, vol. 50, no. 5, (2012), pp. 11-14.

[6] L. Y. Zheng and S. C. Wang, "Approaches to Improve the Process Quality of Thin-Walled Workpiece in NC Machining", Acta Aeronautica, vol. 2, no. 2, (2001), pp. 424-280.

[7] Y. Q. He, "Study on Application of Force Models and Machining Deformation for Milling Process of ThinWalled Workpieces (Master Thesis)", Xi'an, Xi'an Technological University, (2008).

[8] W. S. Yun and D. W. Cho, "Accurate 3-D cutting force prediction using cutting condition independent coefficients in end milling", International Journal of Machine Tools \& Manufacture, , vol. 4, no. 1, (2001), pp.463-478.

[9] K. Wu, N. He, C. Jiang, L. Li and L. He, "Study on Mechanistic Model of End Milling", Journal of Nanjing University of Aeronautics \& Astronautics, vol. 34, no. 6, (2002), pp. 553-556.

[10] K. Wu, N. He, W. Liao and L. He, "Modeling Instantaneous Milling Force Based on Analysis of Machining Errors of Thin-Walled Parts", Journal of Applied Sciences, vol. 23, no. 6, (2005), pp. 631-634.

[11] L. Wang, Y. Ke and Z. Huang, "Experimental Study on Milling-Force Model in Aviation Aluminum-Alloy", China Mechanical Engineering, vol. 14, no. 19, (2003), pp. 1684-1686.

[12] S. N. Meng, "Mechanical Machining Technology Handbook", Beijing, Machine Industry Press, (1991).

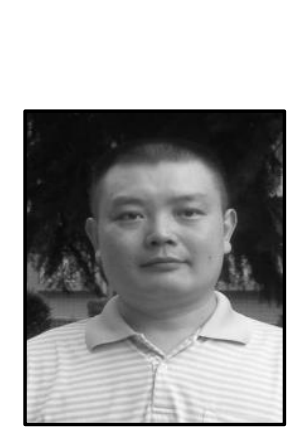

\section{Authors}

Yan Cao received his $\mathrm{PhD}$ degree in Mechanical Engineering from Xi' an Jiaotong University in 1999. He is currently a professor in Xi'an Technological University. His research interests are in the areas of CAD/CAPP/CAM/NC, Virtual Manufacturing, and Manufacturing Informationization.

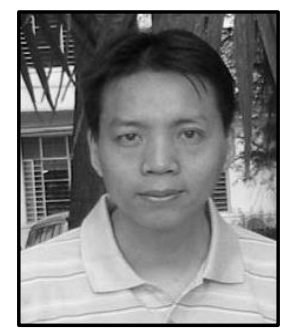

Yu Bai received his $\mathrm{PhD}$ degree in Aerospace Manufacturing from Northwestern Polytechnical University. He is currently an associate professor in Xi'an Technological University. His research interests are in the areas of NC machining, CAD/CAM, digital integrated manufacturing, and manufacturing system management. 


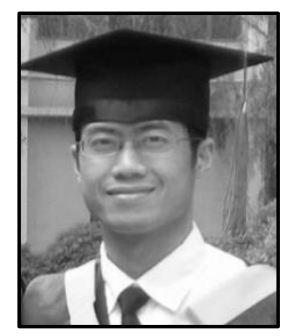

Yongqiang He received his MS degree in Mechanical Manufacturing Automation from Xi'an Technological University. His research interests are in the areas of $\mathrm{NC}$ machining and CAD/CAM.

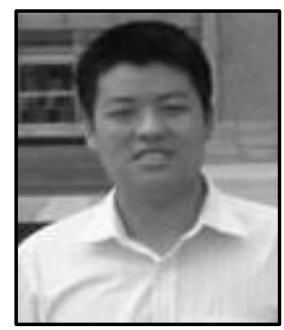

Jianhui Tian received his $\mathrm{PhD}$ degree from Hunan University. He is currently an associate professor in Xi'an Technological University. His research interests are in the areas of computational mechanics, engineering simulation and Computer Aided Engineering.

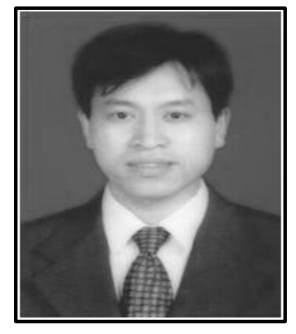

Yunlong Li currently is a senior engineer in Xi'an Jiaotong University. His research interests are in the areas of NC machining, CAD/CAM, and quality management. 